\title{
The Doctor-Patient Relationship Management in the Modern Hospital Management
}

\author{
Na Wang \\ Department of Anesthesiology \\ The First Hospital of Jilin University \\ Changchun, China \\ wangna080613@163.com
}

\author{
Jinguo Wang* (corresponding author) \\ Department of Urology \\ The First Hospital of Jilin University \\ Changchun, China \\ wangjinguolily@163.com
}

\begin{abstract}
To strengthen the management of the doctorpatient relationship and maximize attraction to patients to promote the development of the hospital. Customer relationship management is a modern management with which the enterprise copes with the market competition and establishes a set of management pattern which takes the customer as the center. It is performed by managing customer resources. Provide customers with satisfactory products and services. Hospitals establish longterm, stable, the close relationship of mutual benefit with customers. Today, in the fierce competition in the medical market, hospital managers should use the customer relationship management idea.
\end{abstract}

\section{Keywords-Doctor-patient relationship, management, law}

\section{INTRODUCTION}

Health experts think the doctor-patient relationship is a contractual relationship that doctors must provide technical medical service, the second point is the emotional relationship which humanity medical service, it is not mandatory, but it is the "lubricant" in the doctor-patient relationship. For a correct understanding of the doctor-patient relationship we must improve the current "doctor-patient deadlock" premise and establish a scientific system of the doctor-patient relationship management which is the foundation of maintaining a good doctor-patient relationship.

\section{DOCTOR-PATIENT RELATIONSHIP MANAGEMENT}

Customer relationship management (CRM), as a management phenomenon already exist, however, as a kind of mature management idea and management technology is applied to hospital management, is the rise in recent years. American marketing association defines CRM simple as: to assist enterprises to establish good relationship with customers, make both of us benefit management mode type.

CRM is a special use management and economics. Hospital customer relationship management (at customer relationship management HCRM for short), is the enterprise CRM management experience for reference, the service idea, into hospital management, business process, marketing strategy, customer service and the setup of the "patient-centered" management system. HCRM emphasizes hospital to customer demand as the center, there is a very important concept, and namely the hospital should be carried out a full range of customer relationship management [1]. The essence of customer relationship management (CRM) is a customer's ultimate satisfaction as the goal, through interacting with each customer, understand the reality demand and potential demand, establish lasting, long term win-win relationship with customers one by one, tailored for customers and provide personalized health care services. In medical market competition intensifying, the hospital management is more and more aware of the importance of marketing and I put the "customer" concept to phase in the hospital management. Establish hospital customer relationship management system aims to introduce the purpose of the marketing idea, is under the condition of market economy an innovation of the medical service management project. Customer relationship management is not only a kind of technology, and in essence, is a kind of "take customer as this" the management idea, management concept and management strategy. Hospitals and enterprises, customers are always one of the important factors, it is necessary to introduce customer relationship management, hospital's customer relationship management (CRM) we may call it "patient relationship management" again.

It seems to the hospital, the customer is the most important assets of the hospital, must sincerely care their situation and needs, and not just want to sell to them. But despite all of the employees are responsible to care for the customer is still not enough. Because individuals in various aspects ability and the ways of service, as well as the feeling of customers for medical choice is different, so it is necessary to establish a system for customer service, the cumulative customer data, customer demand for system analysis, and make the data in each contact with the customer, can fully use.

\section{A. The basic concept of doctor-patient relationship management is the doctor-patient relationship is the marketing concept.}

First, the customer relationship management is the core of hospital marketing management, in the implementation of CRM need to build a customer database, hierarchical management to different customers. Hospital customer database individual customer database and customer database, individual customer databases mainly hospital outpatient and customers as the object, the group customer database to 
peripheral units and service agreement has been signed or will be and hospital unit as an object. Individual customer database is mainly to collect: name, gender, age, address, occupation, telephone, email, special interests, visits to the college time, medical departments and service content (diagnosis), pay, pay a return visit whether the grievances and processing conditions, etc. To individual customers on the basis of we will continue to do a telephone pays a return visit, for some chronic diseases and old customers to do a good job in regular return visit at the same time to take advantage of letter, email, etc. do regular contact, is necessary for special customer came to visit [2].

Group customer data mainly collected: company (units) name, address, telephone, fax, address, email, manager or director's name, business scope, the number of employees, the employee's care contacts and relationships with hospitals, etc. For group customers mainly come to visit, to give health seminars at the same time, free clinics and health examination, the regulations issued by the hospital is favorable to the college.

\section{B. Customer management methods}

On both sides of the mutual relationship between doctors and patients and affect each other. Notice to the customer's information, its main function is in essence is the process of communication with customers and achieve effective communication, establish and maintain hospital and customer relationships. They should make full use of modern means, to provide a full range of services, such as: telephone registration, remote service, expert consultation, complaints, and suggestions and so on.

Doctor "home visits" habits have keep up with the situation. Therefore, the hospital each employee sets up the thought of "customer first" philosophy, takes "customer" active service, to right to cater to customers' requirements."

Analyze customers, mainly is to figure out what hospital customer basic types, characteristics and buying behavior and their different needs, and based on the analysis of customer differences influence on hospital income. Customers when buying any product or service to the hospital always face various risks; include economic interests, product features, quality and so on. In order to strive for and guarantee the customer, the hospital should make all sorts of reasonable commitment, and to keep his promise.

Foreign scholars on the definition of medical quality: think of medical quality is composed of structure, process and results of the three combinations, with the minimum of danger and the least cost and the most appropriate health state of patients. Simply put, is to do good curative effect, short course, low cost, high degree of satisfaction, and recognized by the quality of the society [3]. Establish good hospital customer relationship management system will help to shorten the distance between the medical guest, foster and expand the ranks of loyal customers, thus more closely with customers to establish longterm friendly relations of cooperation, establish and perfect the hospital customer service center system, let the customer get the biggest satisfaction, let the hospital gain maximum benefit. At the same time also can reflect the hospital new unique brand and culture, to achieve continuous improvement and cross hospital.
The establishment of customer relationship management is effective to improve the doctor-patient relationship. Ensure that all citizens of basic medical services and health care through a variety of forms to guide the consumer demand, so as to better coordinate the medical service institutions, patients, the government tripartite interactions, prompt medical market healthy, orderly and scientific development.

Customer relationship management is the enterprise to cope with the market competition and establish a set of management pattern take the customer as the center, it through the management of customer resources, to provide customers with satisfactory products and services, with customers to establish long-term, stable and mutual benefit and reciprocity of close relationship, is a kind of strategy to acquire and retain customers [4]. In the medical market increasingly competitive today, hospital managers should use the customer relationship management idea, in order to strengthen the management of the doctor-patient relationship, maximize attract patients, so as to promote the development of the hospital [5].

\section{The combination of modern information technology and the "patient-centered" business process redesign forms a systematic and automated solution.}

The doctor-patient relationship is a special customer relationship, the hospital should adhere to the people-oriented, introducing the science of customer relationship management (CRM), meet the needs of the patient [6]. People-oriented is the inner motive power of hospital development, is the modern management idea, and is also the core of the doctor-patient relationship management. For hospital, people-oriented is ought to be "all patient-centered,"

To strengthen the ideological and political education, sets up the lofty ethics must let all staff to know the importance of the doctor-patient relationship, to a strong ideological and political education of staff, respect patients, establish communication, build harmonious as a specification of service content into the services work, makes every effort to get the trust of the patients. Under the current complex doctor-patient relationship, medical workers have the responsibility is more important, not only in terms of diagnosis and treatment for patients with better service, more want to sincerely communicate with patients, understand the patient's mental state, and try to meet the reasonable requirements of them. As a result, the patient will have a better mood to see a doctor; also will be more actively cooperate with the doctor for treatment [6]. Use the perspective-taking, much station Angle in the patient's thinking, care. Medical staff not only to master the advance d medical technology, service for patients, but also in such aspects as instruments, words and deeds patients satisfactory, this can better improve the quality of hospital services.

Health care is a special industry; the doctor is a special group holds the lifeblood of life. Throughout history, doctors' professional ethics should require the doctor put the patient first. Taking patient as the center provides the service. Adhere to the staff for this, to accelerate the subject development [7].

New kind of hospital management system, and also for the hospital provides a space for the development of each 
employee. Give full play to each employee's enthusiasm, embodies the "patient-centered" service concept, really full participation. Hospital development cannot leave the talents cultivation and construction of the science and technology, the hospital should strengthen medical personnel training, truly the technical operation standardization, improve the quality of basic medical care. Attaches great importance to the talent, and actively introduce "useful" talents and technology [8]. The discipline construction to keep pace with The Times, pay close attention to subject at any time dynamic, strengthen clinical research, improve the level of common disease, frequentlyoccurring disease and the diagnosis and treatment of knotty disorder, to provide quality and efficient medical service for patients. Vigorously implement the strategy of brand, attract source, with the talent to win benefit, expand the market by quality, improve the medical service of various processes, let the patient during the diagnosis and treatment of hospital can feel convenient, comfortable and a full range of care at the hospital [9].

\section{1) Establish a rapid feedback channel}

Build system of hospital leadership Open Day, led by the hospital in person at the hospital with the reception work, listen to the patient and family to the opinions and Suggestions for the work of the hospital, to the scene to the scene to solve the problems of patient and family to, listen to their hospital in all kinds of valuable Suggestions and opinions, so that the hospital can find problems in a timely manner. Regularly for patients and their families to conduct interviews and satisfaction survey, to understand the patient's needs change, strengthen weak links in time management, and eliminate patients are not satisfied [10].

\section{2) Strict management of institutionalization}

Further enhancement of appraisal activities, through self to find problems, analyze problems, thus the rectification problem seriously, establish and improve various rules and regulations, code of conduct and way of rewards and punishments system, rules and discipline the behavior of medical personnel, resolutely put an end to inappropriate behavior in the medical service, seriously do a good job in charge query at any time for patients and their families; Optimizing service process, convenient masses go to a doctor, eliminate the patient in the process of registration fee time is long, long time, take medicine a long time, short treatment time of "three long and one short" phenomenon; Take effective measures to strictly enforce I drug centralized bid procurement system, put an end to drug money with promotional signs of drug in hospital; Learn brothers hospital of advanced management experience, complement each other, propaganda in the treatment of the doctor-patient relationship to emerge in the process of typical, good deeds, good experience, give full play to the role model influence [11].

\section{CONCLUSION}

In order to strengthen the management of the doctor-patient relationship, can accurately understand the patient's needs and the changes of medical market, so that the correct adjustment of hospital management policy, strategy, reduce blindness caused by which the waste of resources. By strengthening the doctor-patient relationship management, can effectively increase the degree of satisfaction, both retain loyal customers, can the hospital stable customer resources. And through the loyal customers promotion and introduction, and constantly attract new customers, in guarantee under the fixed customer resources, and to attract new customers, can more effectively improve the market share of hospital. Through the establishment of patient feedback channels, timely and properly solve the problem of patients reflect, constantly improve the service process, improve service levels, improve the hospital comprehensive competitive ability. In order to strengthen the management of the doctor-patient relationship, build a harmonious doctor-patient relationship, each medical institutions and medical personnel is the key. As a medical institution, we should actively to firmly establish a faithful as the aim of the public and serve for patients, efforts to improve the quality of medical services, through the meticulous and careful service for the patients, make people more recognition of our medical service, make our biggest efforts to build a harmonious doctor-patient relationship.

\section{REFERENCES}

[1] Shan L, Li Y, Ding D, Wu Q, Liu C, Jiao M, Hao Y, Han Y, Gao L, Hao J, Wang L, Xu W, Ren J. Patient Satisfaction with Hospital Inpatient Care: Effects of Trust, Medical Insurance and Perceived Quality of Care. PLos One. 18;11(10):e0164366.Oct 2016.

[2] Valluri KA. Annals Graphic Medicine - Today's Doctor-Patient Relationship. Ann Intern Med. 4;165(7):W12. Oct 2016.

[3] Lv Zhaogong, wang xy, zhang jian. The doctor-patient relationship status quo,causes and countermeasures research: ten cities in China the doctor-patient relationship research. 2010

[4] Shen Fengping. "A doctor" difficulty and high cost of the analysis of the causes and countermeasures. Journal of Chinese modern hospital management journal. 2010

[5] Wang Zhichao. The current doctor-patient conflict reasons of public policy analysis. 2012

[6] Stanley wang, Tian Kan. Our country the doctor-patient relationship status quo series. Journal of health soft science. 2009

[7] Lei Zhi Chun, Jiang Jilu. Discuss how to build a harmonious doctorpatient relationship. China’s hospitals. 2006

[8] Ming wang.Doctor-patient relations. 2008

[9] Astrong zhuang. The doctor-patient relationship, thinking and countermeasure introduction. 2007

[10] Hai TAO. The laws and regulations and professional medical work specification. 2008

[11] Zhao Bang Qin. Medical humanities. 201 